Printed in Great Britain

\title{
Pseudomonas-An attempt at a general classification
}

\author{
BY O. LYSENKO \\ Laboratory of Insect Pathology, Institute of Biology (CSAV), Prague, Czechoslovakia
}

(Received 28 December 1960)

\begin{abstract}
SUMMARY
On the basis of the characterization of 126 strains representing 46 different species of Pseudomonas and 6 species of Aeromonas obtained from different culture collections, a proposal for the taxonomy of the genus Pseudomonas is made. By using various old and new diagnostic methods some 90 different morphological and cultural characters, many obtained by modification of methods and media, were investigated. The iodoacetate test was developed to distinguish between oxidative and fermentative utilization of glucose.

Results were evaluated by the use of punched cards and by the method of strips. The relationships between the established species of Pseudomonas and Aeromonas were shown by using an Adansonian principle and by taxonomic models. On the basis of the results obtained proposals for the definition of the genus Pseudomonas and for re-descriptions of Pseudomonas species are given and the relations to related genera are shown. In the definition of the genus Pseudomonas an attempt to find a more general principle for subdivision within the genus was based on the type of glucose utilization and on the relationships of the species expressed in some other features. This proposal about the taxonomy of pseudomonads is compared with that of Rhodes (1959).
\end{abstract}

\section{INTRODUCTION}

The genus Pseudomonas Migula, 1894 is, as compared with some other genera, a very old one. The taxonomy of the pseudomonads has not kept pace with the recent developments of taxonomy in general, and with microbiological taxonomy in particular.

In the literature more than 500 papers deal with the taxonomy of the genus Pseudomonas but these are mostly devoted to particular problems, only a few are concerned with the basic aspects. This situation was reviewed and discussed by Seleen \& Stark (1943), Haynes (1951), Gaby (1955), Brisou (1958), Rhodes (1959) and others. The result is that more than 140 species are described by Haynes \& Burkholder in Bergey's Manual (1957) and more than 400 names of Pseudomonas species are listed in Krassilnikov's (1949) book; but the species are so ill-defined that the usefulness of the descriptions is doubtful. This is caused first of all by the definition of the genus, which from the time of Migula has been based mainly upon morphology. That the type of flagellation is not an adequate criterion was shown by Bartholomew (1949), Gaby \& Free (1953), Sneath (1956b), and Rhodes (1958); the pigments produced (Turfitt, 1936; Tobie, 1938) and the serology (Köhler, 1957; Burkholder \& Starr, 1948; Naylor, 1954) have not been found suitable bases for taxonomical purposes. 
In recent times biochemical and cultural features have been used for the taxonomy of pseudomonads. On this basis an excellent paper concerning the definition of Pseudomonas fluorescens and of the genus Pseudomonas was published by Rhodes (1959). According to my results the definition of the genus therein is rather narrow, that of the species too broad and sufficient account was not taken of the other species of the genus. One of the main problems in bacterial taxonomy is the lack of a base line or general principle on which species can be founded. What is needed is a system and not only a catalogue of descriptions.

The purpose of the present paper, which is based upon the examination of 125 strains, is to demonstrate that it is possible to develop such a scheme, based on the physiological properties of bacteria in one genus (Pseudomonas), and to show the relations between it and other related genera. I shall also make a proposal about the definition of this genus and several main species.

\section{METHODS}

A total of 126 different strains (isolates) was used. These strains consisted of 46 different determined species of the genus Pseudomonas, 20 undetermined Pseudomonas sp. and 6 determined species of Aeromonas. Twenty-nine strains were fresh isolates obtained by the author; the other 97 strains were obtained from various culture collections and workers. The origin of the strains comprised strains from: man, animals, plants, soil, fresh water, sea, other sources. Strains were kept as freeze-dried desiccates; for the inoculation of diagnostic media they were maintained and transferred on beef peptone agar slopes or yeast-extract peptone agar slopes.

\section{Diagnostic methods}

Cell morphology. Gram reaction, average diameter of organism $(<1 \mu$ or $>1 \mu)$, shape of cell ends, occurrence of curved rods, granulation of cytoplasm, presence of fat granules (stained by Sudan III), presence of capsules or extracellular slime (by nigrosin stain and methods used by Rhodes (1958) and Novelli (1953)), and pleomorphism, were determined with organisms from 2- and 7-day cultures grown on meat peptone agar at $28^{\circ}$. Flagella were stained by Bailey's method (Fisher \& Conn, 1942) and by Fontana's method (Rhodes, 1958); in several cases electronmicroscope examinations were made.

Colonial morphology. The following colonial features were determined with cultures grown on meat peptone agar at $28^{\circ}$ for 2 days : form (punctiform, circular or irregular), elevation (flat, raised, convex or umbonate), margin (entire or not entire), surface (smooth or rough), optical characteristics (transparent or opaque).

Appearance on agar slope. On meat peptone agar incubated for 2 days at $28^{\circ}$ the intensity of growth and pigmentation was observed; good or scant growth, and colour of pigment and its solubility in the medium were noted.

Glucose utilization. This was determined according to Hugh \& Leifson (1953) and by the iodoacetate test, which was developed for this purpose. For the iodoacetate test the following medium was used: Bacto tryptone, $0.1 \%(\mathrm{w} / \mathrm{v})$; yeast extract (Difco), 0.1\% (w/v); NaCl, 0.5\% (w/v); $\mathrm{K}_{2} \mathrm{HPO}_{4}, 0.03 \%$ (w/v); glucose, $1.0 \%$ (w/v); $0.2 \%(w / v)$ of aqueous solution of bromthymol blue $1.5 \%(w / v) ; \mathrm{pH} 7 \cdot 2 \%$. This medium was sterilized by steaming for $30 \mathrm{~min}$. on 3 successive days, and the solution of 
mono-iodoacetate, sterilized by filtration, was added so that the final concentration was $10^{-3} \mathrm{M}$. As control the medium without iodoacetate was used. The medium was inoculated in the normal way, incubated at $28^{\circ}$ and the results read for 5 days. The reaction was considered to be positive when acid was produced in both media and negative when acid was formed only in the control tube (without iodoacetate).

Carbohydrate utilization in peptone media. In a medium containing: proteose peptone, $1.0 \%(\mathrm{w} / \mathrm{v}) ; \mathrm{NaCl}, \mathbf{0 . 5} \%(\mathrm{w} / \mathrm{v})$; carbohydrate, $1.0 \%(\mathrm{w} / \mathrm{v})$; bromthymol blue aqueous solution $1 / 500,1 \cdot 2 \%(\mathrm{w} / \mathrm{v}) ; \mathrm{pH} 7 \cdot 2$; acid and gas production were observed for 6 days at $28^{\circ}$. As carbohydrates glucose, galactose, glycerol and mannitol were tested.

Carbohydrates as sole C-sources. These were examined in chemically defined media according to Seleen \& Stark (1943) and Dowson (1957) with 1.0\% (w/v) of each carbohydrate, namely glucose, lactose, sucrose, fructose, D-galactose, maltose, D-arabinose, L-arabinose, D-mannose, D-xylose, mannitol, glycerol, inositol, salicin. As a control the medium without carbohydrate was used. The occurrence of an acid reaction and growth were determined during incubation for 7 days at $28^{\circ}$.

Organic acids as $C$-sources were used in media according to Seleen \& Stark (1943) and in Koser's medium in which the citrate was replaced by the salt of another organic acid. In the first medium all organic acids were at $0.3 \%(w / v)$; in the second medium the concentrations were as follows $(\%, w / v)$ : formate, $0 \cdot 1$; oxalate, $0 \cdot 1$; acetate, 0.2 ; benzoate, 0.3 ; lactate, 0.1 ; succinate, 1.0 ; malonate, 1.0 ; malate, 1.0 ; D,L-tartrate, 1.0; citrate, 1.0. Phenol $\mathrm{red}(1 / 500)$ added at $0.6 \%(\mathrm{w} / \mathrm{v})$ was used as the $\mathrm{pH}$ indicator. Alkaline reaction and growth greater than that in the control medium without $\mathrm{C}$-source was regarded as positive; it was read after 7 days.

Oxidation of phenol, ethanol or gluconate. Ethanol and phenol oxidation was determined in the medium of Dowson (1957) with phenol $0 \cdot 1 \%(w / v)$ or ethanol $0.5 \%(w / v)$. For the production of acetic acid from ethanol Stanier's method (1947) was used. Gluconate oxidation was determined by the method used by Sneath $(1956 a)$. All tests were read after incubation for 7 days at $28^{\circ}$.

Hydrolysis of aesculin, starch, cellulose and pectin. Hydrolysis of starch was tested in 5 -day cultures grown at $28^{\circ}$ in yeast extract agar containing $0.2 \%(w / v)$ starch, with Lugol's iodine solution; and the aesculin agar plate method (Sneath, 1956a) after 4 days incubation. Ability to attack cellulose was determined in the medium of Alarie \& Gray (1947) during incubation for 2 weeks; pectate hydrolysis was observed according to Dowson (1957).

Litmus milk. The reactions in litmus milk were determined after incubation for 2 weeks at $28^{\circ}$.

Phenylalanine, indole, and Voges-Proskauer (VP) tests. The phenylalanine test was made according to the method described in Report (1958); indole was determined by Kovac's reagent added to tryptone medium cultures after 1 week of incubation; the VP test was made by Barritt's method in medium with $(\%, w / v):$ Bacto peptone, 0.5 ; dipotassium phosphate, 0.5 ; glucose, 0.25 ; galactose, 0.25 ; after 14 days of incubation.

$\mathrm{N}$-sources and urease production. The utilization of ammonium chloride as $\mathrm{N}$ source was tested in Dowson's medium (1957) with galactose; utilization of nitrite (at $\mathbf{0 . 0 5 \%}$, w/v) in Koser's medium with galactose; utilization of urea in Dowson's 
medium with urea and phenol red as $\mathrm{pH}$ indicator. This latter medium was prepared as a liquid, as well as in solid form. The reactions in all these media were observed for 6 days.

Nitrate reduction to nitrite. For nitrate reduction to nitrite three media were used: (a) Peptone medium of the composition $(\%, w / v)$ : Bacto peptone, 1.0; $\mathrm{NaCl}, 0.5 ; \mathrm{KNO}_{3}, 0 \cdot 1 ; \mathrm{pH} \mathrm{7 \cdot 0.}$ (b) Defined medium of Seleen \& Stark (1943). (c) Defined medium used by Rhodes (1959). Nitrites were determined after incubation for 7 days by adding Griess reagents and observing gaseous nitrogen in Durham tubes; the result was controlled by the zinc test.

Ammonia formation. Production of ammonia was tested after incubation for 5 days in medium containing $1.5 \%(\mathrm{w} / \mathrm{v})$ peptone by adding Nessler's reagent.

Decarboxylases. Ability to form decarboxylases of ornithine and lysine, and arginine dihydrolase was tested by Moeller's method (1955); results were determined after incubation for 3 and 5 days.

Proteolytic activity. For liquefaction of gelatin three tests were adopted: (a) yeast extract broth containing $15 \%(\mathrm{w} / \mathrm{v})$ gelatin; $(b)$ plain gelatin medium, $15 \%(\mathrm{w} / \mathrm{v})$ gelatin in water; $(c)$ Frazier's method. The results were read after 5 days, 2 weeks, and 5 weeks. Casein digestion was determined in litmus milk after incubation for 14 days and on milk agar plates after incubation for 3 days. For lecithinase $\mathrm{C}$ production the method of Knight \& Proom (1950) was used.

Lipolytic activity. The lipolytic activity on olive oil was determined by the method of Jones \& Richards (1952) as used by Rhodes (1959) and by the method of Bulder (1955). The results were noted after 3 days.

\section{Pigmentation}

Pyocyanine. Production of pyocyanine was investigated in the liquid medium of Burton, Campbell \& Eagle (1948) and in Gessard's agar (Simon, 1956). After 7 days of incubation at $28^{\circ}$ pyocyanine was determined by extraction into chloroform at alkaline $\mathrm{pH}$ values (blue) and back into water at acid $\mathrm{pH}$ values (crimson) (Wetmore \& Gochenour, 1956).

Fluorescin. For the determination of fluorescin the following media were used: (a) beef peptone agar prepared from fresh meat; $(b)$ medium of Georgia \& Poe (1931). This pigment was determined by its fluorescence under ultraviolet radiation after incubation for 7 days at $28^{\circ}$.

Melanin and other pigments. The tyrosine medium described by Starr (1946) and by Burkholder \& Starr (1948) was used to examine for 'melanin' formation; incubation was for 14 days.

Iodinin and chlororaphin were determined in all the above pigmentation media and on three other media: $(a)$ asparagine, $0.3 \%(\mathrm{w} / \mathrm{v})$; bipotassium phosphate, $0.05 \%(w / v)$; glycerol, $0.5 \%(w / v)$; magnesium sulphate, $0.02 \%(w / v)$; ferrous

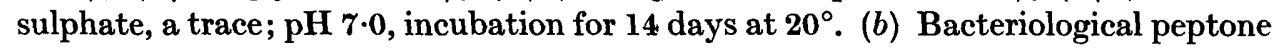
(Oxoid), $1.0 \%(\mathrm{w} / \mathrm{v}) ; \mathrm{NaCl}, \mathbf{0 . 5} \%(\mathrm{w} / \mathrm{v}) ;$ yeast extract (Oxoid), $0.3 \%(\mathrm{w} / \mathrm{v})$; glucose, $0.5 \%(\mathrm{w} / \mathrm{v})$; incubation at $20^{\circ}$ for 21 days. (c) Malt agar (Oxoid); incubation at $20^{\circ}$ for 21 days.

$\mathrm{H}_{2} \mathrm{~S}$ production was detected by the micro-test used by Rhodes (1959).

Haemolysis. Ability to haemolyse red blood cells was determined after incubation for 3 days on sheep blood agar plates. 
Reduction of dyes. Reduction of litmus was examined in litmus milk after incubation for 14 days; methylene-blue reduction was examined by the method of Topley and Wilson's Principles (1946, p. 369).

$\mathrm{NaCl}$ tolerance. Ability to grow in the media containing different concentrations of $\mathrm{NaCl}$ was tested in yeast extract broth and agar with 3.0, 5.0 and 6.5\%(w/v) of $\mathrm{NaCl}$, respectively. Results were noted after incubation for 7 days.

Resistance to pteridine derivative 0/129. Sensitivity to compound 0/129 was tested according to Rhodes (1959).

Resistance to bile was tested on yeast extract agar plates containing 10 or $40 \%$ $(\mathrm{w} / \mathrm{v})$ of Bacto ox-gall.

Resistance to antibiotics was tested on agar plates by using tablets containing the following concentrations of antibiotics: penicillin, 10 i.u.; streptomycin, 20 $\mu \mathrm{g}$.; chloramphenicol, $20 \mu \mathrm{g}$.; chlortetracycline, $100 \mu \mathrm{g}$; oxytetracycline $50 \mu \mathrm{g}$.

The initial $p H$ value for growth. The test for ability to grow at $\mathrm{pH} 5 \cdot 5$ and $8 \cdot 5$ was made according to Rhodes (1959).

Thermal death points. Two points were tested, $56^{\circ}$ for $10 \mathrm{~min}$. and $42^{\circ}$ for 2 days. Both tests were carried out in water baths and broth was used as the medium.

Effect of temperature on growth. The ability to grow at $5^{\circ}, 10^{\circ}, 37^{\circ}$ and $42^{\circ}$ was tested in broth, yeast extract broth and on meat peptone agar slopes. For $5^{\circ}$ and $10^{\circ}$ a refrigerator and for $37^{\circ}$ and $42^{\circ}$ water baths were used.

Catalase and oxidase production. Catalase was determined in 2-day cultures grown in broth by adding two drops of hydrogen peroxide. For oxidase formation the Kovacs (1956) method was used.

\section{Inoculation of media}

Inoculations were made from 1- or 2-day cultures on agar slopes. For tests in which the degree of turbidity was to be examined, broth cultures were used and inoculation was made by a very small loop; later the method used by Rhodes (1959) was adopted. Each test was repeated at least once during a period of 2 years.

\section{The stability of characters to lyophilization}

The influence of lyophilization on some of the features was determined in $\mathbf{9 0}$ cultures. The following characters were examined: glucose utilization in Hugh \& Leifson's medium, utilization of citrate, formate, acetate, malonate, lactate, tartrate and oxalate in Koser's medium, nitrate to nitrite reduction in peptone medium and Seleen \& Stark's medium, liquefaction of gelatin, production of pyocyanine in Burton's and Gessard's media, production of fluorescin in the medium of Georgia \& Poe, production of brown pigment on Gessard's medium, growth in $5 \%(\mathrm{w} / \mathrm{v}) \mathrm{NaCl}$ and growth at $37^{\circ}$ and $42^{\circ}$. These tests were carried out as described above. The cultures were lyophilized in horse serum containing $7.5 \%(\mathrm{w} / \mathrm{v})$ glucose and maintained for 1 year before examination. After this time the ampoules were opened and the tests were repeated.

\section{Recording the results}

Two methods were used : punched cards and the 'method of strips'. All tests were coded and according to the code the characters were put on the punched cards. On these cards were also recorded the descriptions found in the literature. This 
method was very useful for rapid sorting and determination of correlations between the characteristics. The 'method of strips' was made by recording the features of all strains in a table; this was photographed and a print was cut in strips so that each strip represented one strain. The strips were sorted so that similar strains were put together to form groups. This method was found to be very useful for making a table to show a complex comparison of the strains. The relationship between the strains was also calculated by the method described by Sneath (1957) and expressed by models (Lysenko \& Sneath, 1958). The final scheme was obtained on the basis of these methods.

\section{RESULTS}

It is impossible to present in a short form all the results obtained. Therefore I propose first to give brief general characterizations of all the strains and then to make proposals for the definition of the genus and a redescription of the main species.

\section{The characters of the strains examined}

\section{Morphological characters}

Cell morphology. All strains were Gram-negative except Pseudomonas iodinum strains. The cells were less than $1 \mu$ in diameter, in some strains the ends were pointed; most cells were straight but occasionally slightly curved rods occurred; this was not typical and did not correspond to other features. The presence of granulation of the cytoplasm and the arrangement of cells were not the same for all pseudomonads. The presence of extracellular slime, as described by Rhodes (1958), was a common feature but its intensity might vary, especially in old strains.

Polar flagella occurred in 106 strains, 18 were without flagella and 2 strains, not pseudomonads, possessed peritrichous flagella. The predominant type of flagellation was 1-2 flagella per cell. The importance of flagellation has been discussed by many workers and most recently by Rhodes (1959), and it is generally agreed that the type of flagellation is not an important feature in pseudomonas taxonomy.

Colony morphology. All types and combinations of characters described above occurred in our strains. Many Pseudomonas aeruginosa strains were lysogenic. The predominant type of colony was circular or irregular, transparent and smooth. These characters could not be correlated with other features and their taxonomic importance seemed to be very limited.

Agar slant. All strains grew very well.

\section{Cultural and biochemical characters}

Types of glucose utilization. In Hugh \& Leifson's medium glucose was utilized under anaerobic conditions by 25 strains but late and indistinct reactions were observed in 17 other strains. This test was useful only as a rough guide and did not give such accurate results as the iodoacetate test.

Iodoacetate test. Acid, and sometimes gas, in the control medium but not in iodoacetate medium was produced by only 9 strains; 4 of them were aeromonads, the remaining 5 cultures were not pseudomonads. Fourteen strains did not produce acid in either medium but these strains produced a slight turbidity in iodoacetate medium. 103 strains produced acid in both media, but in 2 strains obtained as Aeromonas sp. gas was not produced in iodoacetate medium, which indicates that 
these strains had two pathways by which glucose was utilized, oxidative and glycolytic.

The iodoacetate test was found extremely useful for differentiation between oxidative and fermentative utilization of glucose and was valuable for distinguishing between Pseudomonas and Aeromonas species. It was, however, difficult to state to what extent the glycolytic fermentation was inhibited. This test gave better results than that used by Hugh \& Leifson, but we should use carefully the terms 'oxidative or fermentative metabolism' as, even though the glycolytic pathway is blocked by iodoacetate, we know nothing about the other pathways by which glucose may be utilized. The absence of the Embden-Mayerhof system was demonstrated in different pseudomonads (Norris \& Campbell, 1949; Campbell \& Norris, 1950; Entner \& Stanier, 1951 ; Entner \& Doudoroff, 1952; Gibbs \& DeMoss, 1954), but on the other hand only in $P$. saccharophila could glucose be utilized in five different ways (Palleroni \& Doudoroff, 1957).

The use of well studied enzyme inhibitors, such as dinitrophenol, sodium azide and others, may be useful for better distinguishing the principal metabolic systems, which might be used for a better classification.

Carbohydrate utilization in peptone media. In peptone medium glucose was utilized by 108 strains, galactose by 103 strains, glycerol and mannitol by 29 strains. Gas was produced only by the aeromonads. Other carbohydrates were attacked only by the strains of Pseudomonas synxantha and aeromonads.

Carbohydrates as the sole $C$-source. The utilization of carbohydrates in both media was practically the same, but the use of growth as an indicator of utilization was made difficult because, as described by Rhodes (1959), slight growth might occur in the control tube without $\mathrm{C}$-source. For this reason, only those tubes were classified as 'having growth', in which there was a marked difference in turbidity between the control and test. The frequency of the reactions in 126 strains was expressed as acid reaction growth only: galactose, 125/1; glucose, 84/10; xylose, $74 / 17$; glycerol, 72/14; mannose, 77/21; mannitol, 77/9; fructose, 68/26; L-arabinose, $62 / 24$; D-arabinose, $33 / 26$; inositol, 38/24; sucrose, $20 / 10$; salicin, $16 / 49$; maltose, 14/69; lactose, $3 / 6$.

Organic acids as the sole C-source in Koser's medium were utilized by 126 strains as follows, the results being expressed as the number showing an alkaline reaction/ growth only: citrate, 110/6; malonate, 85/20; formate, 81/9; benzoate, 62/21; acetate, $49 / 40$; lactate, $38 / 9$; succinate, $35 / 6$; tartrate, $15 / 39$; oxalate, $3 / 24$; and malate, $4 / 25$. Seleen \& Stark's medium gave generally slightly different results; the main differences were in, \% positive in Koser: \% positive in Seleen \& Stark, acetate, 71:56; lactate, 37:79; tartrate, 43:67; and oxalate, 21:0. The differences could be explained by different concentrations of organic acids in both media; similar differences were found by Rhodes (1959).

The cultures gave practically identical results in citrate, malonate, and formate before and after lyophilization, an increased number of positive reactions in acetate and tartrate, but a decreased number in lactate after drying. It was found that the initial $\mathrm{pH}$ of the medium played an important role. More positive results were obtained in media with initial $\mathrm{pH} 6 \cdot 5$ or 6.0 than at $\mathrm{pH} 7 \cdot 0$. As was said in connexion with the previous tests, the colour changes of the indicator was important for standard checking of the tests. 
Oxidation of phenol, ethanol and gluconate. In 126 strains the results (expressed as strong positive: weak positive) were: phenol (12:24), ethanol (41:0) and gluconate $(86: 4)$. The ethanol liquid medium gave sharper results than ethanol agar.

Hydrolysis of aesculin, cellulose and pectin. Starch was hydrolysed by 8 strains of which only one was a pseudomonad; cellulose and pectin were not attacked. In aesculin positive reactions were given by 35 strains; weak positive by 7 strains.

Litmus milk. After 14 days' incubation in litmus milk, of 126 strains tested 20 strains gave a strongly alkaline reaction, 1 weakly alkaline, 6 strains acidified and 20 strains produced curd. Peptonization and litmus reduction is given under casein digestion and reduction of litmus.

Phenylalanine, indole and VP tests. The phenylalanine test was positive only once in an aeromonad. The indole test was positive only in 3 aeromonad cultures. The Voges-Proskauer reaction was strongly positive in 19 strains and weakly positive in 1 strain. Most of these strains were classified later as Pseudomonas synxantha.

$N$-sources and urease production. Nitrites were utilized strongly by 73 strains and weakly by 23 strains, ammonium chloride strongly by 48 , weakly by 60 , and urea strongly by 47 and weakly by 18 strains. Urease was formed by 30 strains. For urease better results were obtained in the liquid medium, because the solid medium gave a higher percentage of uncertain results.

Nitrate reduction. In 3 media the results in 126 strains were as follows, results expressed as number of strains producing $\mathrm{NO}_{2} / \mathrm{N}_{2}$ : in peptone medium, 194/46; in Seleen \& Stark's medium, 97/41; in medium used by Rhodes, $82 / 43$. The reduction was influenced by lyophilization so that the ability to reduce nitrates in both media was increased in total, but some strains lost this feature. The results were also influenced by the concentration of nitrates and by the viscosity of the medium. Some strains which gave negative results in the previous media gave weakly positive results in the medium with $0.01 \% \mathrm{KNO}+0.3 \%$ agar; the strains did not produce the same results when the concentrations of nitrates and agar were varied.

Ammonia formation from peptone. Only 2 strains, neither pseudomonads nor aeromonads, did not form ammonia; the remaining 124 strains formed ammonia.

Decarboxylases. Arginine dihydrolase was produced strongly by 90 strains, weakly by 5 strains; ornithine decarboxylase strongly by 15 strains, weakly by 4 strains; lysine decarboxylase strongly by 15 strains, weakly by 4 strains. As will be shown later the arginine test was found to be very useful for pseudomonad taxonomy.

Proteolytic activity. Gelatin liquefaction occurred in 96 strains and the results were practically the same in all media. Strains which did not liquefy gelatin in broth or by Frazier's method were also negative in plain gelatin medium. The speed and the form of liquefaction was variable and seemed not to be important for taxonomy. This characteristic was relatively stable as only 7 strains lost it when the strains were freeze-dried and kept for 1 year.

Casein digestion occurred in 91 strains tested in litmus milk and in 82 on milk agar. The difference was perhaps caused by the different length of incubation.

Lecithinase was formed by 47 strains.

Lipolytic activity. Olive oil was decomposed by 92 strains and 31 strains grew without marked lipolytic activity; 3 strains did not grow. 
Pigmentation

Pyocyanin. In the 2 media used pyocyanin was produced by 26 strains on Gessard's medium and by 24 strains in defined medium. This character was stable, as only 2 strains lost it and 1 gained it after the strains were preserved as freeze-dried cultures.

All the strains producing pyocyanine were later found to be Pseudomonas aeruginosa.

Fluorescin. In defined media fluorescin was produced by 35 strains but on beefpeptone agar by 71 strains. This difference could be explained by the fact that the method for determination of fluorescin is not standardized (cf. Elliot, 1957), and with different media gives different results. Nevertheless, the better results were obtained in media prepared from fresh meat than from dried commercial products. The differences were caused by the age of cultures, because by lyophilization fluorescin formation was lost in $20 \%$ strains in defined medium and in $22 \%$ on agar medium.

Melanin and other pigments. In defined tyrosine medium none of the strains formed melanin, but some of the strains produced fluorescin or pyocyanin. A brown pigment soluble in the medium occurred often on beef-peptone agar and on Gessard's agar. The intensity of pigmentation was variable and was influenced by the length of incubation.

Iodinin was formed only by Pseudomonas iodinum strains on malt agar. Chlororaphin occurred only in some cultures of $\boldsymbol{P}$. chlororaphis in defined medium but this feature was very variable and did not occur in all the strains of this species. $\boldsymbol{P}$. aureofaciens produced orange or yellow pigment corresponding with the description of Haynes et al. (1956).

The strains that produced other pigments on different media are described below. One strain of Pseudomonas pseudomallei produced slight yellow pigment, a strain of $\boldsymbol{P}$. rubescens formed red pigment as did some of the strains later classified as $P$. synxantha or Aeromonas salmonicida. The best pigmentation occurred on milk agar, egg yolk agar or in gelatin after longer incubation at $20^{\circ}$.

Other culture and physiological properties

$\mathrm{H}_{2} \mathrm{~S}$ production. Using the micromethod, hydrogen sulphide was produced by 40 strains after $4 \mathrm{hr}$. incubation and by 23 strains after $15 \mathrm{hr}$.

Haemolysis. Strong haemolysis was caused by 31 of 126 strains and 16 showed a weaker reaction.

Reduction of dyes. Methylene blue was reduced by 25 strains within $2 \mathrm{hr}$. and by 25 strains within $24 \mathrm{hr}$. The taxonomic significance of the test was doubtful as it predominated in aeromonads and in Pseudomonas aeruginosa and did not correlate with other properties.

Litmus was reduced by 100 strains and this feature correlated with casein digestion.

$\mathrm{NaCl}$ resistance. All strains grew in medium with $3 \% \mathrm{NaCl}, 107$ with $5 \% \mathrm{NaCl}$, but only 69 in $6.5 \% \mathrm{NaCl}$. This feature was not influenced by lyophilization.

Resistance to pteridine derivative 0/129. Only the strains of Pseudomonas fragi, $\boldsymbol{P}$. rubescens and $\boldsymbol{P}$. denitrificans, as they were later classified, were inhibited by this compound. 
Bile resistance. In the medium with $10 \%$ bile all strains except 1 of Pseudomonas rubescens grew; with $40 \%$ bile 2 non-pseudomonads did not grow. Some strains formed an opalescent precipitate surrounding the growth but this feature did not correspond with any other feature.

Antibiotic resistance. The sensitivity of the strains to antibiotics was as follows, expressed as strong/weak: penicillin, $1 / 1$; streptomycin, 68/24; chloramphenicol, 40/48; chlortetracycline, $27 / 6$; and oxytetracycline, 33/6. The strain highly sensitive to penicillin was not a pseudomonad, the one weakly sensitive was an aeromonad. Pseudomonas aeruginosa strains were mainly sensitive to chloramphenicol and streptomycin, weakly or not sensitive to the tetracycline antibiotics. In other strains the sensitivity was very variable.

The initial $p H$ for growth. Most of the strains produced distinct growth at $\mathrm{pH} \mathbf{5 . 5}$ and at 8.5. Only 15 strains did not grow at $\mathrm{pH} 5.5$ and 4 at $\mathrm{pH} \mathrm{8.5}$. The usefulness of these tests was found to be limited, as pseudomonads were able to change the $\mathrm{pH}$ on the alkaline side quickly. For this test buffered media should be used.

Thermal death point. Thirty-four strains were sensitive to exposure at $56^{\circ} / 10 \mathrm{~min}$., but this property did not correspond with any other feature. Exposure at $42^{\circ} / 2$ days gave better results. Twenty-nine strains which were not able to grow at $42^{\circ}$ survived the exposure. This test in combination with the ability to grow at $42^{\circ}$ was valuable for distinguishing Pseudomonas aeruginosa from other pseudomonads.

Effect of temperature on growth. All strains grew well between $18^{\circ}$ and $30^{\circ}$. At $42^{\circ}, 34$ strains grew in broth; in other media the results were similar but solid media in the incubator produced uncertain results. The best method was to use liquid medium incubated in a water bath.

At $37^{\circ}$ growth occurred in 106 cultures, at $10^{\circ}$ in 84 , and at $5^{\circ}$ in 56 cultures. In this case, too, clearer cut results were obtained in liquid medium. The inability to grow at $5^{\circ}$ and at $10^{\circ}$ correlated with the growth at $42^{\circ}$ in Pseudomonas aeruginosa cultures. Ability to grow at $42^{\circ}$ was not affected by the lyophilization and was considered stable. Growth at $37^{\circ}$ was an unstable feature; while primary isolation could not grow in subculture, many strains became adapted to grow at this temperature and most strains from collections grew at $37^{\circ}$. For taxonomic purposes the ability to grow at $5^{\circ}$ and $42^{\circ}$ could be a valuable characteristic.

Catalase and oxidase formation. In my series of strains an oxidase positive reaction was detected in 100 cultures; negative reactions occurred in some non-pseudomonads, in strains later classified as Pseudomonas synxantha, in one strain of $\boldsymbol{P}$. pseudomallei and in $\boldsymbol{P}$. iodinum. This test was very useful for the taxonomy of pseudomonads.

Only 4 strains did not form catalase; 2 were not pseudomonads, 1 was an aeromonad and 1 was the culture of Pseudomonas pavonacea.

When the results of features examined are compared as a whole with those obtained by Seleen \& Stark (1943) or by Rhodes (1959), differences are found. The smaller differences can be explained by the different strains examined; other authors mostly used fresh fluorescin-producing isolates and in this respect their strains were more homogeneous than mine. The marked differences which could not be explained only by this difference occurred mostly in the tests on utilization of carbohydrates or organic acids as C-sources. The results of Rhodes (1959) were on the average $25 \%$ higher than mine, but marked differences were in lactose $(7 \cdot 2 \%$ 
in my series against $90 \%$ in Rhodes), in $\mathrm{D}$-arabinose $(46 \cdot 7 / 80 \%$ ) and sucrose $(23 / 60 \%)$. Discrepancies may be due to the different criteria used for evaluating the results. Rhodes used turbidity, whereas in my work only the change of $\mathrm{pH}$ was counted as a positive reaction; turbidity greater than the control was marked as an uncertain reaction. Where a dense turbidity occurred without $\mathrm{pH}$ change, it was scored as a late positive reaction. In my experience sharper results could be obtained by using indicators, and the standardized inoculum was not so important, which made the test more suitable for routine diagnostic purposes.

Having the characters of each strain, the next step was to determine if the named strains corresponded with their original descriptions and to choose representative cultures. Except where the originals were available, the descriptions given in Bergey's Manual (1957) and in Krassilnikov's book (1949) were used and were supplemented by data in papers published in the two last decades. Even though the descriptions of species were mostly very general, vague or incomplete, and the determination made according to them could be doubtful, the revision and clarification of the taxonomy had, in default of better characterization, to be based on them.

It was found that out of the total number of 106 strains sotained as named cultures, representing 40 species of Pseudomonas and 4 species of Aeromonas, 58 strains, including $30 P$. aeruginosa could be taken as representative, 25 strains might be classified as typical; furthermore 17 strains did not correspond to their previous designations and $\mathbf{3}$ of them could not be taken as pseudomonads or aeromonads.

\section{The taxonomic division of the strains}

The work was divided into four steps: (1) to divide the strains in groups according to their similarities, (2) to find the relations between the groups and express them by Adansonian principles, (3) to find the correct names for the groups, and (4) to define the genus and the species. I propose to give only the main points and notes, the detailed results being demonstrated by tables and figures.

The whole series of strains was divided by the sorting methods described into three main groups (the number of strains in the groups is given in the brackets).

(A) A group of 94 strains was divided in two subgroups. The first (a) contained strains later classified as $\boldsymbol{P}$ seudomonas aeruginosa (33 strains), atypical $\boldsymbol{P}$. aeruginosa strains (3), P. aureofaciens (2), P. chlororaphis (2), P. aeruginosa-P. fluorescens intermediate strains (1), P. fluorescens (9), P. putida (8), P. fluorescens-P. putida intermediate (8) and $P$. ovalis (1).

The variation of characters was least in Pseudomonas aeruginosa and the strains were easily distinguished from the others. Closely related to $\boldsymbol{P}$. aeruginosa were the strains classified as $\boldsymbol{P}$. aureofaciens and $\boldsymbol{P}$. chlororaphis. These species were the most biochemically active within this subgroup. The remaining strains formed a series characterized by great variability mainly in carbohydrate utilization, organic acid utilization and in proteolytic activity. To divide them on the basis of the individual characters was impossible. Similar difficulties were demonstrated by many other workers, e.g. Clara (1934), Seleen \& Stark (1943), Stanier (1947), Rhodes (1959), and thus the great number of different descriptions of Pseudomonas species might be explained. Therefore for the differentiation of these strains two more general criteria were chosen: utilization of carbohydrates as a unit and proteolytic activity. In this way it was possible to distinguish two species: Pseudomonas 
fluorescens and $\boldsymbol{P}$. putida. The first was characterized by the low activity in utilization of carbohydrates and high proteolytic activity; in the latter these properties were reversed. Between these extremes some intermediate forms occurred. $P$. ovalis was selected as an example of the less reactive species.

The second subgroup (b) was divided into 11 species, later classified as Pseudomonas pseudomallei (2 strains), P. diminuta (2), P. stutzeri (1), P. denitrificans (1), $P$. iodinum (1), P. atlantica (1), P. rubescens (1), P. pavonacea (1), P. geniculata (1), and $\boldsymbol{P}$. taetrolens (1, and 2 intermediate).

Because strains were few in number it was not possible to establish the range of variation of these species and thus the definitions of the species are of limited value. But many of the] strains were holotypes and it was necessary to determine their taxonomic position as there was some relation between them and the species of the first subgroup. The characteristics of these species, which were obtained by the comparison of individual strains, each taken as a unit, are given in the Table 1 and the full descriptions are given at the end of this paper.

(B) The second group was composed of 12 strains later classified as Pseudomonas synxantha, 2 strains labelled as Aeromonas spp. and 4 strains identified as aeromonads. With these strains it was more convenient to determine the acid production from carbohydrates in peptone than in the defined medium because of the wide range of variation which occurred in the latter medium.

The Pseudomonas synxantha subgroup consisted of a very homogeneous group of strains in which each strain possessed no more than three atypical characters from those listed in Table 2. Strains labelled as Aeromonas spp. were very closely related to $\boldsymbol{P}$. synxantha but the formation of gas indicated their relations to aeromonads.

The aeromonads, represented here by 4 species, were compared and it was found that they could be distinguished from pseudomonads by the lack of oxidative utilization of glucose as indicated by the iodoacetate test.

The characterization of these species is given in Table 2 and Pseudomonas synxantha is defined at the end of this paper.

(C) The last group was composed of 12 different strains which could not be listed in any of the previously described groups and their taxonomic position among pseudomonads was also doubtful. I did not regard these strains as Pseudomonas species and they are not described here.

\section{The relationship between the species}

The methods used by Sneath (1957) and Lysenko \& Sneath (1958) were used to show the relations between species. The $S$ values calculated from Tables 1 and 2 are given in Tables 3 and 4. The models are shown on Pl. 1.

As may be seen the grouping described above was fully confirmed. There are close relationships between species $\boldsymbol{P}$ seudomonas aeruginosa, $\boldsymbol{P}$. aureofaciens and $\boldsymbol{P}$. chlororaphis, between $\boldsymbol{P}$. fluorescens, $\boldsymbol{P}$. putida and $\boldsymbol{P}$. ovalis, and between the species of Aeromonas. On the basis of these relationships and on the characters of species the definition of the genus was developed. The general principles used to formulate the definition of the genus given at the end of this paper need explanation here.

The central group of the genus (see scheme in Fig. 1) is connected via Pseudomonas taetrolens with $P$. synxantha which is the connecting link to the genus Aeromonas. This main line is first of all characterized by the change from the fully 


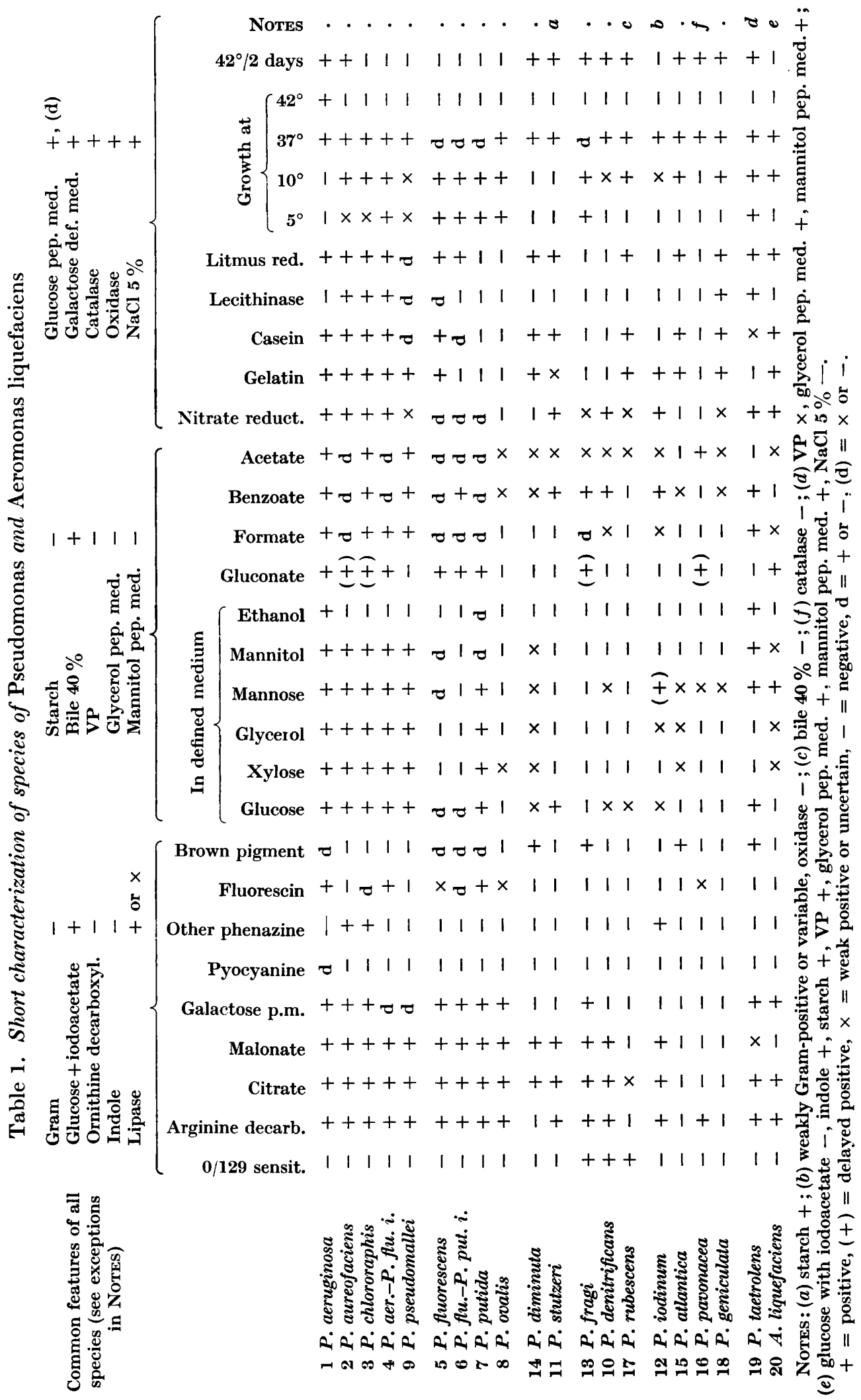




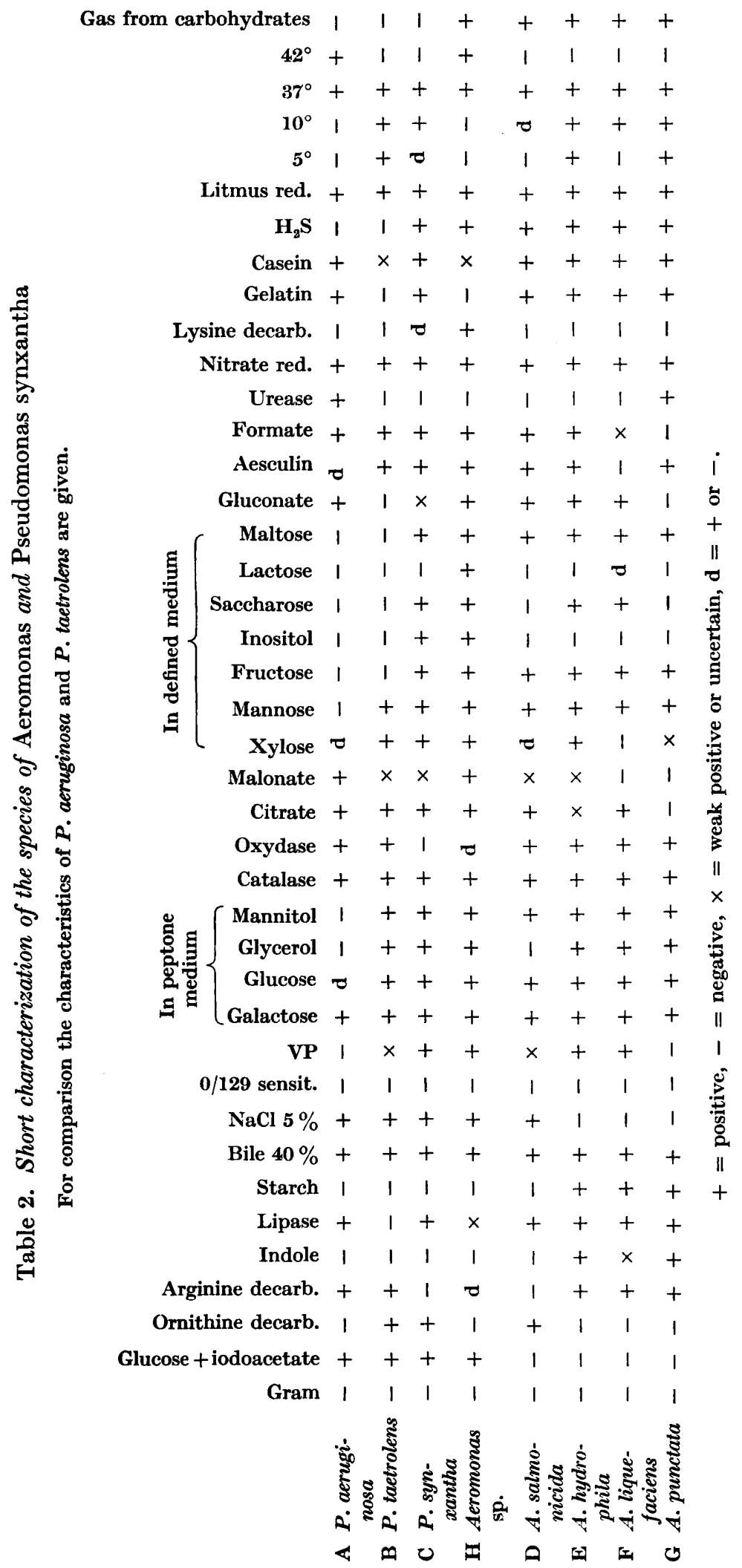


Table 3. $S$ values of Pseudomonas spp.

Table 3 was derived from Table 1 as follows: for a particular comparison between 2 species, $\mathrm{S}=n /\left(n_{s}+n_{d}\right)$, where $n_{s}$ is the number of features for which they are both positive, and $n_{d}$ is the number of features for which one is positive and the other negative. The entries,$+(+)$ and $x$ in Table 1 were counted as positive, - as negative and $d$ as NC (no comparison made).

$\begin{array}{rl}1 & P . \text { aeruginosa } \\ 2 & P . \text { aureofaciens } \\ 3 & P . \text { chlororaphis } \\ 4 & P . \text { aer. }-P . \text { fluor. } \text { inter. } \\ 5 & P . \text { fluorescens } \\ 6 & P . \text { fluor. }-P . \text { put. inter. } \\ 7 & P . \text { putida } \\ 8 & P . \text { ovalis } \\ 9 & P . \text { pseudomallei } \\ 10 & P . \text { denitrificans } \\ 11 & P . \text { stutzeri } \\ 12 & P . \text { iodinum } \\ 13 & P . \text { fragi } \\ 14 & P . \text { diminuta } \\ 15 & P . \text { atlantica } \\ 16 & P . \text { pavonacea } \\ 17 & P . \text { rubescens } \\ 18 & P . \text { geniculata } \\ 19 & P . \text { taetrolens }\end{array}$

100

78,100

$79,97,100$

$79,90,96,100$

$72,79,86,91,100$

$61,68,72,73,94,100$

$73,75,80,83,78,80,100$

$53,57,61,61,77,84,81,100$

$77,88,92,91,79,72,86,69,100$

$61,60,60,60,59,63,65,62,72,100$

$68,68,63,58,68,70,52,58,62,75,100$

$61,65,71,62,59,59,65,56,72,67,55,100$

$55,59,58,54,69,81,66,74,62,77,60,54,100$

$78,76,69,69,62,56,61,65,74,53,70,57,55,100$

$56,60,56,57,56,50,50,48,59,46,60,41,48,73,100$

$49,38,38,39,48,45,50,48,38,46,42,33,50,38,42,100$

$55,60,55,57,64,57,46,48,57,71,78,48,61,61,60,44,100$

$55,62,59,58,62,55,44,48,62,50,71,50,54,61,74,48,74,100$

$62,72,76,70,68,66,58,52,70,63,60,47,60,62,52,35,52,56,100$

Table 4. $S$ values of some Pseudomonas and Aeromonas spp.

Table 4 was derived from Table 2 in the same way as Table 3 was from Table 1

\begin{tabular}{|c|c|}
\hline A P. aeruginosa & 100 \\
\hline B $P$, taetrolens & 56,100 \\
\hline C P. synxantha & $52,69,100$ \\
\hline H Aeromonas sp. & $56,59,82,100$ \\
\hline D A. salmonicida & $57,63,80,72,100$ \\
\hline E A. hydrophila & $48,63,75,69,75,100$ \\
\hline F A. liquefaciens & $47,53,66,68,69,88,100$ \\
\hline G A. punctata & $42,53,56,52,59,79,82,100$ \\
\hline
\end{tabular}

oxidative pseudomonad to the fully fermentative aeromonad pathway of glucose utilization. The relationships between the species of the central group are shown by the $S$ values in Table 3, where the figure 100 indicated identity. The relation between $\boldsymbol{P}$. aeruginosa and $\boldsymbol{P}$. taetrolens lies in the presence of arginine dihydrolase, oxidase, and in the inability to produce acid from inositol, fructose and maltose in peptone medium (cf. Table 2); relations to $P$. synxantha are seen in acid production from glycerol, mannose and mannitol in peptone medium in the presence of ornithine decarboxylase and in slight production of acetoin.

The relationships between Pseudomonas synxantha and the species of Aeromonas are best seen in the strains labelled as Aeromonas spp. which showed both fermentative and oxidative metabolism of glucose, i.e. glucose is utilized with acid production in the medium with or without iodoacetate, gas is formed only in the absence of iodoacetate.

The most closely related species of Aeromonas to Pseudomonas is A. salmonicida; the similarity with $\boldsymbol{P}$. aeruginosa and $\boldsymbol{P}$. taetrolens may be seen in indole, starch, 
glycerol, oxidase, inositol, malonate, growth at $42^{\circ}$ and pigmentation; the relationship with $\boldsymbol{P}$. synxantha is based on VP, glycerol, mannitol, maltose and ornithine.

The other species of Pseudomonas are considered to be transitions between the central group to other genera. The relationship between $\boldsymbol{P}$. geniculata and Acetobacter was pointed out by Steel \& Walker (1957). The sensitivity to the pteridine derivative shown by $\boldsymbol{P}$. fragi, $\boldsymbol{P}$. rubescens and $\boldsymbol{P}$. denitrificans might indicate a relationship with Vibrio (cf. Shewan, Hodkiss \& Liston, 1954; Rhodes, 1959). The lack of activity in carbohydrates and organic acids in connexion with weak arginine dihydrolase activity of $\boldsymbol{P}$. pavonacea could indicate a relationship to Alcaligenes

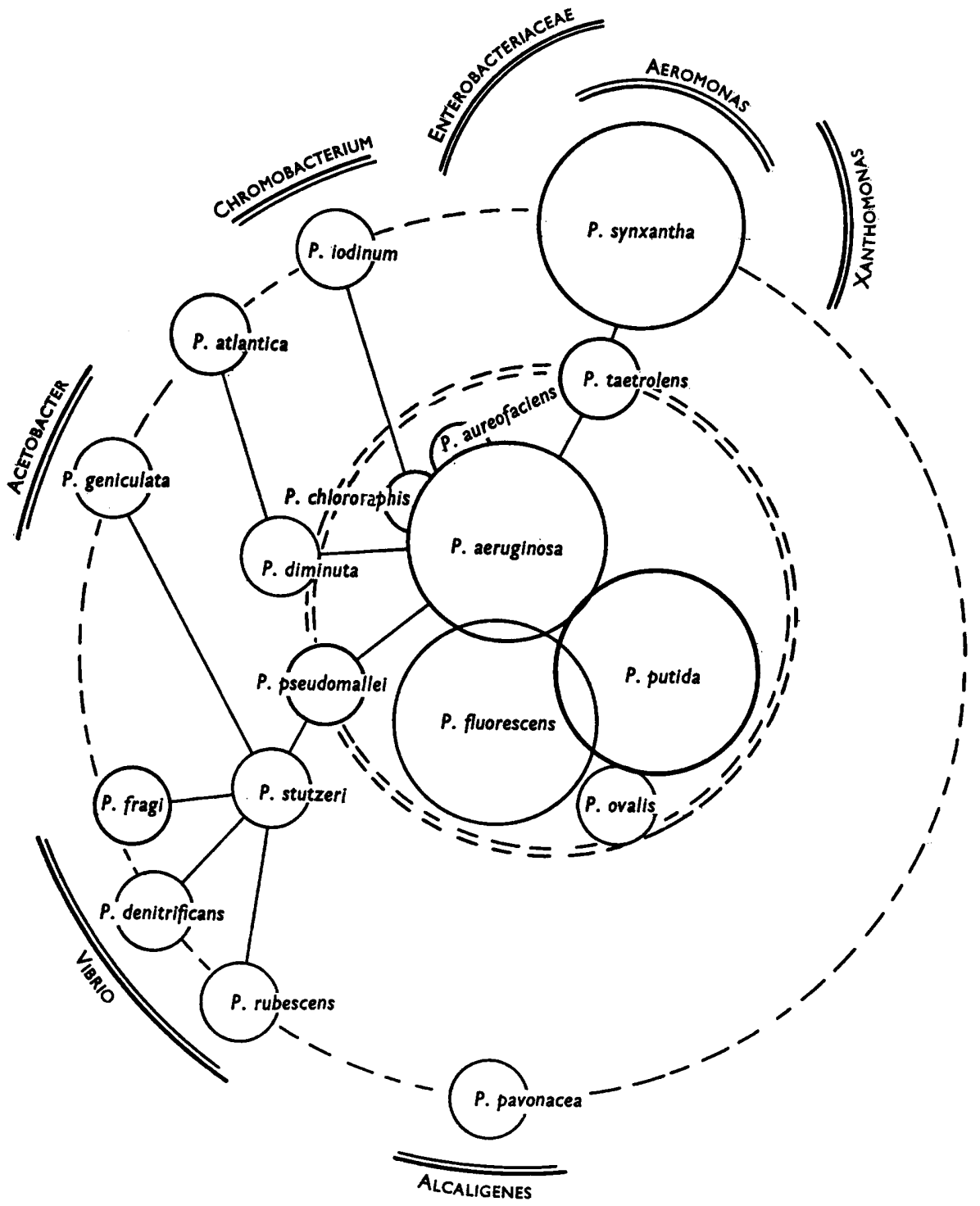

Fig. 1. The relationships between the species of Pseudomonas and between the genus Pseudomonas and related genera. - - , the boundaries of the genus Pseudomonas; $===$, the boundaries of the central group. For details see text. 
(cf. Sherris, Shoesmith, Parker \& Breckon, 1959). The similarity between $P$. iodinum and Chromobacterium as well as the relationship between $\boldsymbol{P}$. aeruginosa and $\boldsymbol{P}$. pseudomallei may be seen from the paper by Sneath \& Cowan (1958). A relationship between Aeromonas and Serratia (Enterobacteriaceae) was reported by Stevenson (1959) and some features of Xanthomonas, Cloaca and Serratia spp. are very similar to $P$. synxantha.

In some cases in redescribing species the synonymy was developed partly on cultures which corresponded to the original descriptions, and in other cases on the original descriptions which could not be supported as cultures were not available. According to the Bacteriological Code (1958, Rule $9 d$ ), when a type culture is not available, characterization depends on a published description and logically, therefore, it is possible to state the synonymy by comparing descriptions. I think that the taxonomy of a group may be simplified and many ill-defined species eliminated in a legitimate way. It is obvious that this solution must be subjective, because the identifications based on an ill-defined description will be doutbful, but any other solution could be just as subjective and the only criterion is convenience.

While establishing the synonymy a more general nomenclatural problem appeared. Some of the previously described species should have been classified as intermediate strains, e.g. occurring between Pseudomonas fluorescens and $\boldsymbol{P}$. putida but in the Bacteriological Code there is no direction to cover such a situation. There are at least three possibilities: (1) to list them under one of the species, but this is inadvisable as their descriptions do not fully correspond to the definitions of any species; (2) to take them for organisms of uncertain position, but this is not correct, because their taxonomic position can be found; (3) the third possibility is that a new species or subspecies should be created for them, but this also is not correct, because between these newly created species further intermediates will occur and logically new species should be created ad infinitum. I think that the existence of intermediate forms must be recognized and should be taken into consideration in the Bacteriological Code.

\section{DISCUSSION}

In this paper I have tried to find criteria for the more general classification of the genus Pseudomonas. An attempt has been made to develop a grouping which is not merely a catalogue of strains but a system having general rules.

My results can be compared in many details with the views and results of other authors, such as Haynes \& Burkholder (1957) in Bergey's Manual and Rhodes (1959).

The monograph of Brisou (1958) is characterized by the limited number of characters used for species definition without knowledge of the range of variability; therefore, many species are described.

The recent work of Rhodes (1959) in most ways corresponds to the modern requirements of taxonomy. Some of the differences between her work and mine can be explained by the use of different strains and different methods of reading reactions in some media. In addition, differences in the general conceptions and in the evaluation of results, may be summarized as follows: (1) The description of the genus given by Rhodes was based on the examination of isolates which had been selected according to their production of 'characteristic green-yellow water-soluble fluorescin' but this feature was not included in the final definition of the genus or 
of the species Pseudomonas fuorescens. (2) The genus definition, based on the definition of one species, was narrow, and it was not clear if other species, e.g. the type, $P$. aeruginosa, or other related species, corresponded to it. (3) In the definition the relationship to other related taxa was not taken into consideration.

The last point is important in basic taxonomy and in the past has not received the attention it merits. The definition of a higher taxon, e.g. genus, is not simply the sum of the features common to the lower taxa, just as the bacterial cell is not only the simple sum of enzymes. This additive concept has been common in microbiology and is, I think, a practice that has kept our taxonomy in the stage of catalogues and hindered the development of a system. The characterization of species as the sum of the characters common to all strains, is analogous to defining a forest as the simple sum of trees in it.

On the other hand, my results fully confirm those of Rhodes that the strains classified by her as Pseudomonas fluorescens, which in my scheme correspond to the species $\boldsymbol{P}$. fluorescens, $\boldsymbol{P}$. putida and the co-intermediates, have a very high range of variability and that the species must have a broader basis. It is a matter of convenience whether they should be established as two species or as one. I think that it is better to distinguish two species, as $\boldsymbol{P}$. fluorescens was described as gelatin-positive, and to establish $\boldsymbol{P}$. putida for gelatin-negative strains. This feature was correlated to some extent with the carbohydrate utilization. As the strain, which was proposed by Rhodes as a neotype for Pseudomonas fluorescens, can be classified as an intermediate between $\boldsymbol{P}$. fluorescens and $\boldsymbol{P}$. putida, a new neotype for $P$. fluorescens was selected.

Finally I should like to emphasize that this taxonomy is only an attempt to show how a more general system might be developed. The taxonomic position of some species is not clear and further knowledge may necessitate a change of their position; moreover, the main principle used here may be found to be of general application and not specific for pseudomonads. But the main point I wish to make is the possibility that a more general scheme in which the intermediate forms can be placed should be found so as to prevent the repeated changes in the taxonomy and nomenclature.

\section{A PROPOSED CLASSIFICATION OF THE GENUS PSEUDOMONAS}

Genus Pseudomonas Migula, 1894, nom. cons.

Syn.: Chlorobacterium Guillebeau, 1890.

The genus Pseudomonas is composed of species of Gram-negative, aerobic, nonsporeforming, rod-shaped bacteria, which are physiologically a dynamic group. In their physiological characteristics the different forms are linked to one another and form a continuously graded series. The genus as a whole is characterized as follows: straight or slightly curved Gram-negative rods, mostly motile by polar flagella. Spores are not formed. The diameter of cells is less than $1 \mu$. Extracellular slime may be formed.

Glucose utilization is not inhibited by iodoacetate in the concentration of $10^{-3} \mathrm{M}$. Glucose is utilized oxidatively, gas is not formed from carbohydrates.

Grow well in peptone media, most species grow in defined media in which glucose or galactose are the only $\mathrm{C}$-sources and ammonium phosphate the only $\mathrm{N}$-source. 
May form pigments which are green, blue-green, yellow, orange, light or dark brown or fluorescent yellow-green; pigments are mostly soluble in the medium.

If acid is produced from glucose and galactose in peptone medium, acid is not formed from mannitol and glycerol (except $\boldsymbol{P s e u d o m o n a s t a e t r o l e n s ~ a n d ~} \boldsymbol{P}$. synxantha). Citrate is generally utilized as the only C-source. Arginine dihydrolase may be formed, ornithine decarboxylase is not formed (except P. synxantha). Lipolytic. Indole is not formed, starch is not hydrolysed (except $\boldsymbol{P}$. stutzeri), acetoin is not produced, cellulose and pectin are not attacked. Phenylalanine test is negative.

Not sensitive to penicillin. Pteridine derivative $0 / 129$ does not act bacteriostatically (except species transitional to the genus Vibrio). Ammonia is formed from peptone. Grow in media with 10 and $40 \%$ bile and in medium with 3 and $5 \% \mathrm{NaCl}$.

Aerobic. Oxidase (except Pseudomonas synxantha, $\boldsymbol{P}$. iodinum) and catalase (except $P$. pavonacea) are formed. Growth occurs at $18-30^{\circ}$, some species grow at $5^{\circ}$, others at $42^{\circ}$. Growth at initial $\mathrm{pH} 5 \cdot 5-8 \cdot 5$.

Mostly saprophytic, but some species may be pathogenic.

The type species is Pseudomonas aeruginosa (Schroeter) Migula, nom. cons.

The principle of the taxonomy within the genus

The taxonomy is based on species-centres, which are defined by all the physiological features so that an individual centre shares some common features but has others that are exclusive. Between the species many intermediate forms may exist. The main line of variation is based on the transition from forms possessing purely oxidative utilization of glucose to forms which both oxidize and ferment glucose.

The central group within the genus consists of species possessing exclusively an oxidative metabolism of glucose, utilizing citrate and malonate as the only $\mathrm{C}$-source, utilizing nitrites and ammonium chloride as $\mathrm{N}$-source, oxidizing gluconate, forming arginine dihydrolase. Lactose is not utilized; they are not sensitive to pteridine derivative $0 / 129$. Oxidase and catalase are formed. To this group belong the species $\boldsymbol{P}$ seudomonas aeruginosa, $\boldsymbol{P}$. fluorescens, $\boldsymbol{P}$. putida, $\boldsymbol{P}$. chlororaphis, $\boldsymbol{P}$. aureofaciens and transitional forms as $\boldsymbol{P}$. pseudomallei, $\boldsymbol{P}$. ovalis and $\boldsymbol{P}$.taetrolens in which some of the above features may be absent. The species are established according to their carbohydrate and nitrogen metabolism, $P$. aeruginosa being the most active species and $\boldsymbol{P}$. ovalis the least.

With this central group are linked further species which are transitional to related genera, such as Aeromonas and Xanthomonas (Pseudomonas synxantha), Chromobacterium ( $\boldsymbol{P}$. iodinum), Vibrio (P. fragi, P. rubescens, $\boldsymbol{P}$. denitrificans), Acetobacter $(P$.geniculata) Alcaligenes ( $P$. pavonacea). The taxonomic setting of these transitional species is not final, as it depends upon further similar elaboration of the related groups.

Pseudomonas aeruginosa (Schroeter) Migula, 1900, nom. cons.

Syn.: Bacterium aeruginosum Schroeter, 1872; Bacillus pyocyaneus Gessard, 1872; Pseudomonas pyocyanea Migula, 1895.

Cells. Gram-negative rods, spores are not formed, motile by 1-2 polar flagella. Cells form irregular slimy capsules or irregular extracellular slime. 
Colonies. On meat peptone agar: circular or irregular, flat, raised or umbonate, margin is entire or irregular, surface smooth or rough, transparent or opaque. Frequently lysogenic.

Agar slope. Good growth. Some strains form pigment which is soluble in the medium.

Pigmentation. Fluorescin, pyocyanine and brown pigment are formed. The production of one of these pigments may be absent. Non-pigmenting strains may occur.

Physiological and cultural characters are given in Table 5.

Some strains are pathogenic for animals, man or insect. Widely distributed in nature (man, animals, plants, water, soil).

Strain CCEB 481 (i.e. Culture Collection of Entomogenous Bacteria, Laboratory of Insect Pathology, Prague) is proposed as neotype.

Pseudomonas aureofaciens Kluyver et al. 1956.

This species is closely related to Pseudomonas aeruginosa. Pyocyanine and fluorescin and the brown pigment are not formed. An orange or yellow phenazine pigment is formed. The cells possess tufts of polar flagella. Physiological and cultural features are given in Table 5. Occurs in soil.

Strain CCEB 518 (NRRL B-1576) is the lectotype culture.

Pseudomonas chlororaphis (Gignard \& Savegeau) Bergey et al. 1930.

Syn.: Bacillus chlororaphis Gignard \& Savegeau, 1894.

This species is closely related to Pseudomonas aeruginosa. The cells are motile by tufts of polar flagella. Pyocyanine is not formed, fluorescin is sometimes formed. Some strains can form chlororaphin irregularly.

Physiological and cultural characters are given in Table 5.

Occurs in milk, in insects and perhaps widely distributed in nature.

CCEB 292 (NRRL B-560) is proposed as neotype.

Pseudomonas fluorescens (Flügge) Migula, 1895.

Syn.: Bacillus fluorescens liquefaciens Flügge, 1886; Pseudomonas viscosa (Frankland \& Frankland) Migula, 1895; P. septica Bergey et al.1930 (i.e. Bacillus fluorescens septicus Stutzer \& Wsorow, 1927); P. boreopolis Gray \& Thornton, 1928; P. shuylkilliensis Chester, 1901 (i.e. Bacillus fluorescens shuylkilliensis Wright, 1895); P. putrefaciens (Derby \& Hammer, 1931), Long \& Hammer, 1941 ; $P$. cohaerens (Wright, 1895), Chester, 1901.

Cells. Gram-negative rods, spores are not formed, motile by polar flagella, cells form irregular capsules or extracellular slime.

Colonies. On meat peptone agar: circular, flat, raised or convex, entire, smooth, transparent.

Agar slope. Good growth; green, yellow-green or slightly brown soluble pigment.

Pigmentation. Fluorescin or slightly brown pigments may be formed. Some strains are without pigment.

Physiological and cultural characters are given in Table 5. 


\section{Pseudomonas taxonomy}

Note. From the number of 14 different carbohydrates listed in the table which are utilized as the $\mathrm{C}$-sources, 3 carbohydrates are utilized with acid production and 3 others without acid.

Widely distributed in nature.

The strain CCEB 488 is proposed as neotype.

Pseudomonas putida (Trevisan) Migula, 1895.

Syn.: Bacillus fluorescens putidus Flügge, 1886; Pseudomonas striata Chester, 1901 (i.e. Bacillus striatus viridis Ravenal, 1896); P. incognita Chester, 1901 (i.e. Bacillus fluorescens incognitus Wright, 1895; P. rugosa (Wright, 1895), Chester, 1901; P. mildenbergi Bergey et al. 1930; P. convexa Chester, 1901 (i.e. Bacillus fluorescens convexus Wright, 1895); P. eisenbergii Migula, 1900 (i.e. Bacillus fluorescens nonliquefaciens Eisenberg, 1891, P. nonliquefaciens Bergey et al. 1923); P. ambigua (Wright, 1895), Chester, 1901 (i.e. Bacillus ambiguus Wright, 1895); P. salopia Gray \& Thornton, 1928.

Cells. Gram-negative, rods with polar flagella, motile. Extracellular slime is formed irregularly.

Colonies. On meat peptone agar: circular, flat, raised, convex or umbonate; entire, smooth, transparent.

Agar slope. Good growth. Fluorescin or brownish pigment may be formed.

Pigmentation. Fluorescin or slightly brown pigments may be formed.

Physiological and cultural characters are given in Table 5.

Note. In contrast to Pseudomonas fluorescens, acid is formed from 6 carbohydrates of those listed in the table in the defined medium.

Widely distributed in nature.

CCEB 520 is proposed as neotype.

Pseudomonas ovalis Chester, 1901

Syn.: Bacillus fluorescens ovalis Ravenal, 1896.

Cells. Gram-negative, non-sporeforming rods, motile by tufts of polar flagella. Extracellular slime may be formed.

Colonies. On meat peptone agar: circular, flat, entire, smooth, transparent.

Agar slope. Good growth with the formation of yellow-green pigment soluble in medium.

Pigmentation. Fluorescin is formed.

Physiological and cultural characters are given in Table 5.

CCEB 380 (NRRL B-1595) is proposed as neotype.

Pseudomonas pseudomallei (Whitmore) Haynes, 1957

Syn.: Bacillus whitmori Stanton \& Fletcher, 1921; Bacillus pseudomallei

Whitmore, 1913; Malleomyces pseudomallei Breed, 1939; Loefflerella pseudomallei (Whitmore) Gay et al. 1935.

Cells. Gram-negative rods, non-sporeforming, motile, by 1-2 polar flagella. Capsules are not present.

Colonies. On meat peptone agar: small, circular, smooth or rough. Yellowish or white with oil-like lustre.

Agar slope. Good growth, some strains grow slowly. 
Pigmentation. Yellow pigment not soluble in medium occurs in some strains. In older cultures slight brown pigment develops.

Physiological and cultural characters are given in Table 5.

Note. The acid formation in defined and peptone media with carbohydrates is variable in the sense that young and old cultures give different results. Haemolysis of sheep erythrocytes is very weak or may be absent but human erythrocytes are haemolysed.

Pathogenic for man and animals.

The strain CCEB 472 (NRRL B-12) is proposed as neotype.

Pseudomonas fragi (Eichholz, 1902) Huss, 1907 emend. Hussong et al. 1937

Syn.: Bacterium fragi Eichholz, 1902.

Cells. Gram-negative, non-sporeforming rods, motile by polar flagellum. Extracellular slime may be formed.

Colonies. On meat peptone agar medium: circular, flat or raised, entire, smooth, transparent.

Agar slope. Good growth, brownish pigment.

Pigmentation. Brownish pigment, soluble in medium, is sometimes formed in cultures.

Physiological and cultural characteristics are given in Table 5.

Strain CCEB 387 (NRRL B-25, ATCC 4973) is proposed as neotype.

\section{Pseudomonas diminuta Leifson \& Hugh, 1954}

Cells. Gram-negative non-sporeforming rods, motile by polar flagellum. Extracellular slime is formed. In all the cultures slight pleomorphism occurs.

Colonies. On meat peptone agar: circular, umbonate, entire, transparent, smooth.

Agar slope. Good growth.

Pigmentation. In older cultures a brownish pigment soluble in medium occurs.

Physiological and cultural characteristics. See Table 5.

The strain CCEB 513 (NCTC 8545) is the holotype.

Pseudomonas stutzeri (Lehmann \& Neumann) Kluyver, 1942

Syn.: Bacillus denitrificans Burri \& Stutzer, 1895; Bacterium stutzeri Lehmann

\& Neumann, 1896; Bacillus nitrogenes Migula, 1900; Pseudomonas stutzeri

Kluyver, 1942; not Pseudomonas stutzeri Migula, 1900.

Cells. Gram-negative rods, non-sporeforming, motile by a polar flagellum. Extracellular slime is formed only rarely.

Colonies. On meat peptone agar: circular, convex, entire, transparent, smooth. Agar slope. Good growth without pigment formation.

Physiological and cultural characteristics are given in Table 5.

CCEB 522 (NRRL B-927) is proposed as neotype.

Pseudomonas denitrificans Bergey et al. 1923.

Syn.: Bacillus denitrificans fluorescens Christensen, 1903.

Cells. Gram-negative, non-sporeforming rods, motile by 1-2 polar flagella. Extracellular slime may be formed. 
Colonies. On meat peptone agar: circular, flat with an irregular margin, rough, slightly transparent.

Agar slope. Good growth, without pigments.

Physiological and cultural characters. See Table 5.

Occurs in water and soil.

CCEB 525 (NRRL B-1028) is proposed as neotype.

Pseudomonas iodinum (Davis, 1939) Tobie, 1939

Syn.: Chromobacterium iodinum Davis, 1939.

Cells. Gram-variable, especially in the young cultures. Non-motile rods without flagella. Extracellular slime is formed very weakly.

Colonies. On meat peptone agar medium: circular, white, convex, entire, smooth, opaque.

Agar slope. Good growth.

Pigmentation. On malt agar after longer incubation at $20^{\circ}$ a reddish pigment occurs. The production of this pigment, which is a phenazine derivative, is very variable.

Cultural and biochemical characters are given in Table 5.

The strain NCTC 9742 (CCEB 512) is designated as the lectotype.

\section{Pseudomonas atlantica Humm}

Cells. Gram-negative, non-sporeforming rods, motile by polar flagellum. Extracellular slime is rarely formed.

Colonies. On meat peptone agar: very small circular.

Agar slope. Good growth.

Pigmentation. In old cultures brownish pigment soluble in medium.

Cultural and biochemical characters are given in Table 5.

Occurs in sea water.

Note. The strain CCEB 506 (National Collection of Marine Bacteria 301), which was obtained as the type culture, differs in some characters from the original description. In peptone medium it does not form acid from glucose, galactose, glycerol and mannitol, starch is not hydrolysed, acetate and lactate are not used as $\mathrm{C}$-sources, tartrate is used, nitrites are not used as $\mathrm{N}$-sources.

Pseudomonas rubescens Pivnick, 1955

Cells. Gram-negative, non-sporeforming rods, motile by a polar flagellum. Extracellular slime is not formed.

Colonies. On meat peptone agar: circular, convex, entire, smooth, transparent. Agar slope. Good growth.

Pigmentation. On egg yolk agar and milk agar a purple pigment not soluble in medium is formed.

Cultural and biochemical characters are given in Table 5.

Isolated from mineral oils.

The strain CCEB 519 (NRRL B-1651) is the lectotype.

Pseudomonas pavonacea Levine \& Soppeland, 1926

Cells. Gram-negative, non-sporeforming rods, motile by a polar flagellum. Extracellular slime may be formed. Old cells are a little pleomorphic. 
Colonies. On meat peptone agar: circular, convex, entire, smooth, transparent. Agar slope. Good growth and in older cultures a very slightly yellow-green pigment soluble in the medium is formed.

Pigmentation. Very weak and not marked. Might be fluorescin.

Cultural and biochemical characters are given in Table 5 .

The strain CCEB 533 is proposed as neotype.

Pseudomonas geniculata (Wright, 1895) Chester, 1901

Syn.: Bacillus geniculatus Wright, 1895.

Cells. Gram-negative rods. Spores are not formed. Motile by means of polar flagella. Extracellular slime may be formed. In culture pleomorphic forms may occur.

Colonies. On meat peptone agar: circular, convex, entire, smooth, transparent. Agar slope. Good growth.

Pigmentation. Brownish pigment soluble in the medium may be formed.

Cultural and physiological characters are given in Table 5.

Strain CCEB 338 is proposed as neotype.

\section{Pseudomonas taetrolens Haynes, 1957}

Syn.: Pseudomonas graveolens Levine \& Anderson, 1932; not Pseudomonas graveolens Migula, 1900.

Cells. Gram-negative rods, non-sporeforming, motile by a polar flagellum. Extracellular slime is formed irregularly. In old cultures irregular, pleomorphic filamentous forms occur.

Colonies. On meat peptone agar: circular, convex, entire, slightly transparent, smooth.

Agar slope. Good growth.

Pigmentation. Slightly brown pigment is formed in old cultures. Pigment is soluble in the medium.

Physiological and cultural characters are given in Table 5.

Strain CCEB 381 (NRRL B-14) is the holotype.

Pseudomonas synxantha (Ehrenberg) Holland, 1920

Syn.: Pseudomonas lachrymans (Smith \& Bryan, 1915), Carsner, 1918; Bacillus apisepticus Burnside, 1936 (cf. Landerkin \& Katznelson, 1959).

Cells. Gram-negative rods, motile by polar flagella or non-motile. Capsules or extracellular slime not formed.

Colonies. On meat peptone agar: circular, flat or raised or convex, entire, smooth, transparent or opaque.

Agar slope. Good growth.

Pigmentation. Some strains can form brownish or pinkish pigment soluble in the medium.

Cultural and biochemical characters are given in Table 5.

Occurs in insects, on plants, in sea and perhaps widely distributed in nature.

Strain CCEB 293 (NRRL B-780, ATCC 9890) is proposed as the neotype. 

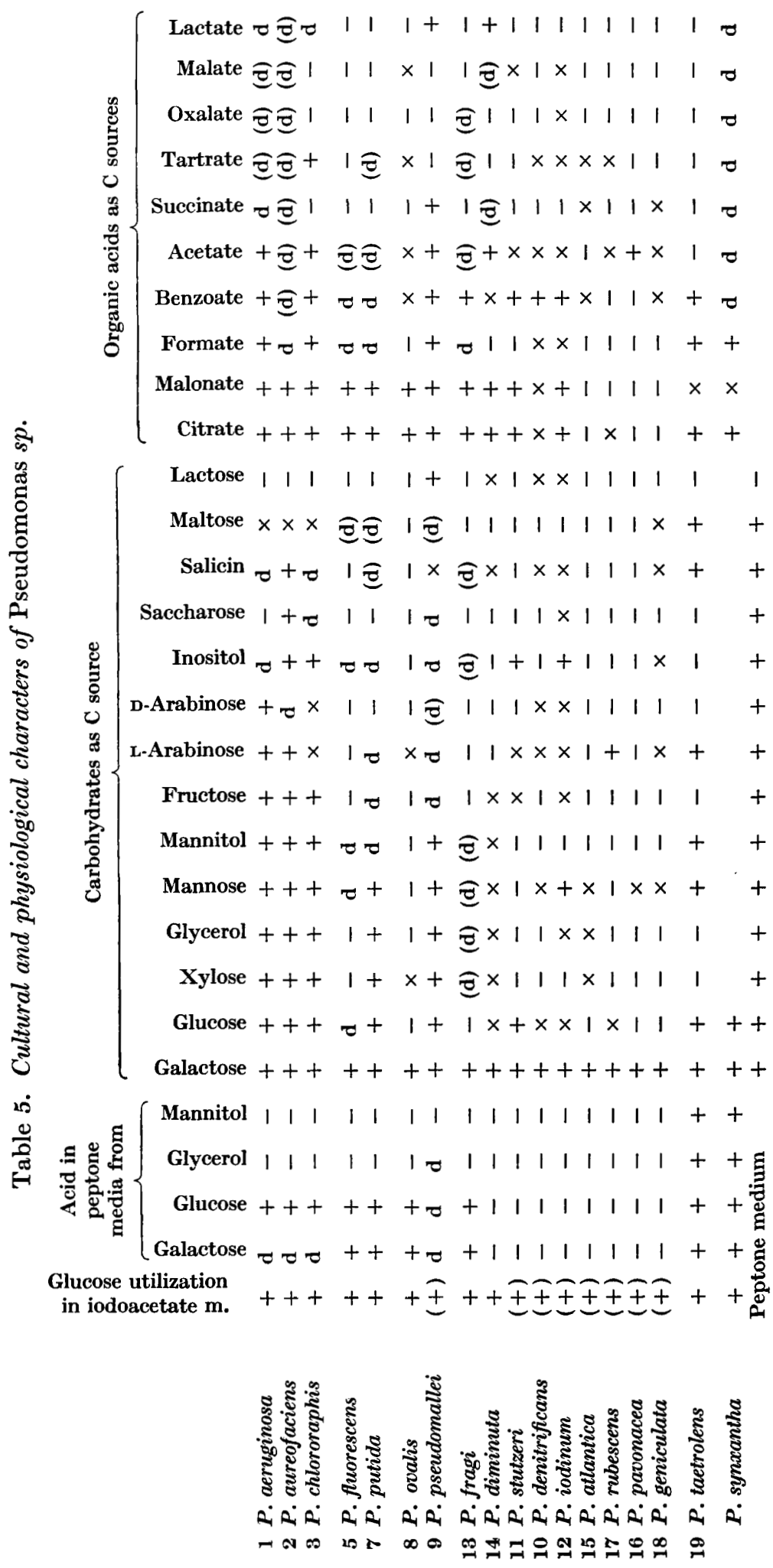
Haemolysis $+\begin{array}{lllllllllllllllll}1 & 1 & 1 & 1 & 1 & 0 & 1 & 1 & 1 & 1 & 1 & 1 & 1 & 1 & 1 & 1 & 0\end{array}$ Lipase $+++\times \times \stackrel{t}{+}++\times \times \times \times++++$

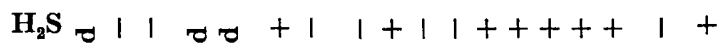

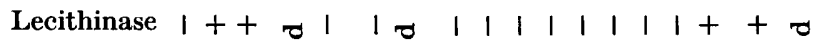
Casein $t+++11+1++11++1+++$ Gelatin $++++11+1+\times 1+++1+1+$

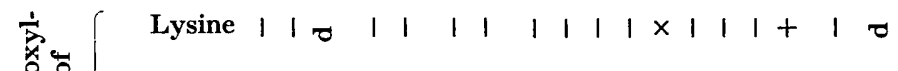

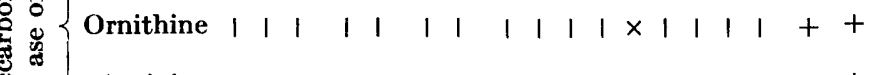
ڤ̆

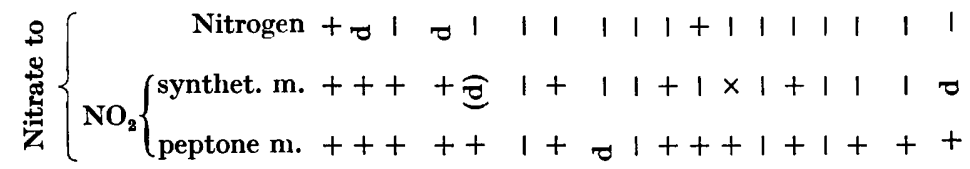
$\mathrm{NH}_{4}$ from peptone ++++++++++++++++++

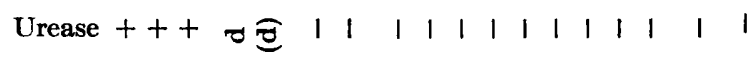

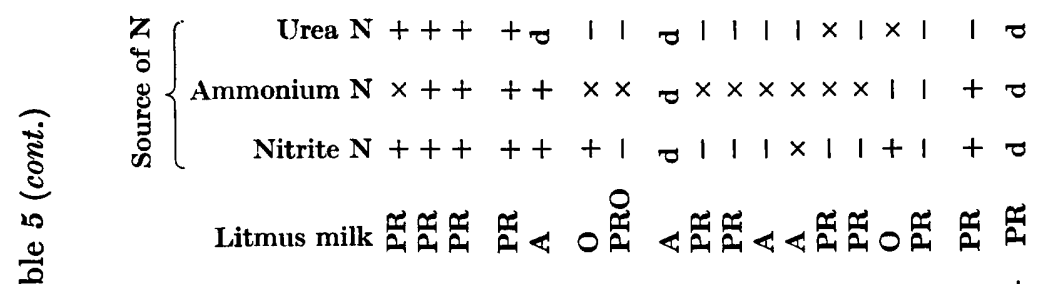

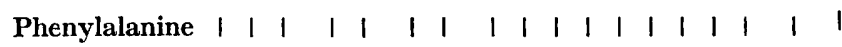
$\begin{array}{llllllllllllllllllll}\text { Indole } & 1 & 1 & 1 & 1 & 1 & 1 & 1 & 1 & 1 & 1 & 1 & 1 & 1 & 1 & 1 & 1 & 1 & 1\end{array}$ $\begin{array}{lllllllllllllllllll}\text { VP } & 1 & 1 & 1 & 1 & 1 & 1 & 1 & 1 & 1 & 1 & 1 & 1 & 1 & 1 & 1 & 1 & x\end{array}$

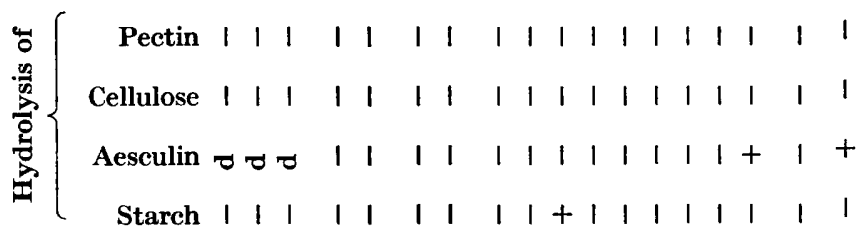

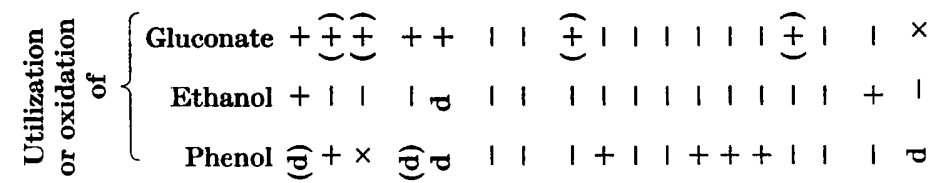

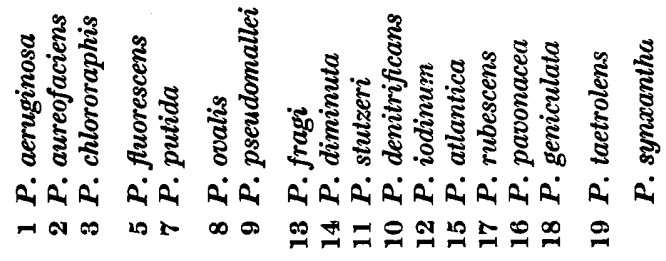




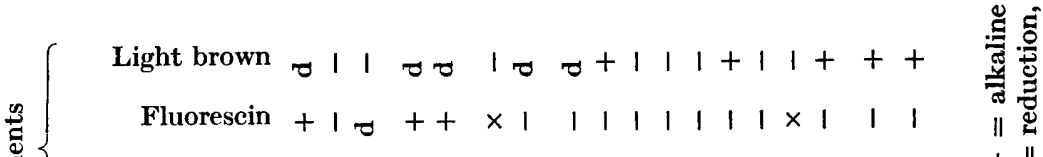
Other phenazine $1+\tau \quad 1 \quad 1 \quad 111111+11111111$

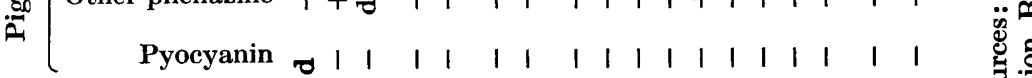

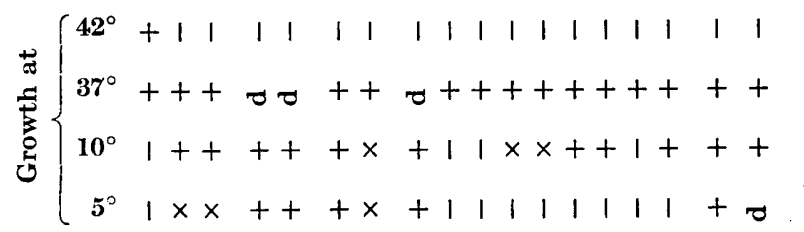

密

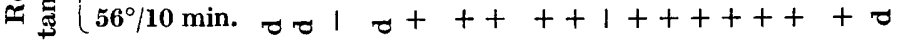

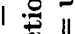

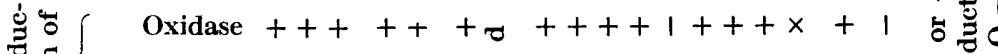
赵胥

Catalase $++++++x+++++1+++$

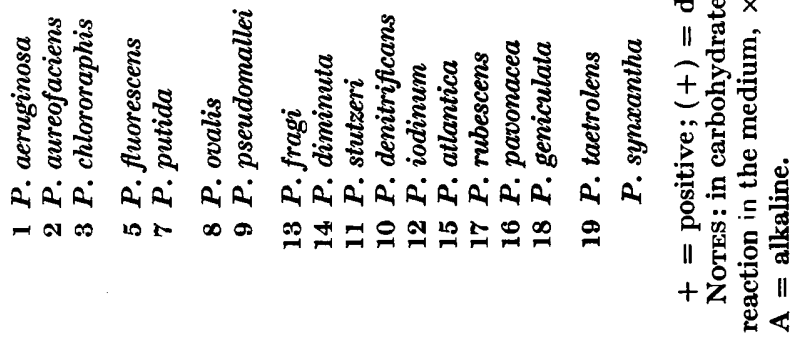


The author wishes to thank Dr W. C. Haynes (Northern Regional Research Laboratory, Peoria, Ill., U.S.A.), Dr J. M. Shewan (Torry Research Station, Aberdeen, Scotland), The National Collection of Type Cultures, London, Dr W. J. Dowson (Botany School, Cambridge), Dr P. H. A. Sneath (National Institute for Medical Research, London), Dr E. A. Steinhaus (University of California, Berkeley, Calif., U.S.A.), and all other research workers who kindly provided strains for study. Dr Muriel E. Rhodes (University of Reading) is thanked for the gift of the pteridine derivative 0/129 and Dr J. M. Shewan for the descriptions of two Pseudomonas species. The author also wishes to thank Academician I. Málek and Dr J. Weiser from this Institute for their interest and help in this work, Dr J. Chaloupka and Dr J. Stárka for valuable advice and Miss Eliška Cerná and Mrs Sha Cha-Yun for technical assistance.

To Dr S. T. Cowan very sincere thanks are expressed for his help with the manuscript and for constructive criticism.

\section{REFERENCES}

Alarie, A. M. \& Gray, P. H. H. (1947). Aerobic bacteria that decompose cellulose, isolated from Quebec soils. Canad. J. Res. C, 25, 228.

Bacteriological Code (1958). International Code of Nomenclature of Bacteria and Viruses. Edited by the Editorial Board of the International Committee on Bacteriological Nomenclature. Ames, Iowa, U.S.A.: Iowa State College Press.

Bartholomew, J. W. (1949). Flagellation of certain species of Pseudomonas as seen with the electron microscope. J. gen. Microbiol. 3, 340.

Bergey's Manual of Determinative Bacteriology (1957). 7th ed. Ed. by R. S. Breed, E. G. D. Murray \& N. R. Smith. Baltimore, U.S.A.: Williams and Wilkins Co.

Brisou, J. (1958). Etude de quelques Pseudomonadaceae. Classification. Bordeaux: A. Baillet.

BuLDER, C. J. E. A. (1955). Some observations on the lipolytic activity of micro-organisms and a new method for its detection. Antonie van Leeuwenhoek J. Microbiol. Serol. 21, 433.

Burkholder, W. H. \& Stark, M. P. (1948). The generic and specific characters of phytopathogenic species of Pseudomonas and Xanthomonas. Phytopathology, 38, 494.

Burton, M. O., Campbell, J. J. R. \& Eagle, B. A. (1948). The mineral requirements for pyocyanin production. Canad. J. Res. C, 25, 15.

CAMprell, J. J. R. \& Norris, F. C. (1950). The intermediate metabolism of Pseudomonas aeruginosa. IV. The absence of Embden-Mayerhof system as evidenced by phosphorus distribution. Canad. J. Res. C, 28, 203.

Clara, F. M. (1934). A comparative study of the green-fluorescent bacterial plant pathogens. Cornell Univ. Agric. Exp. Sta. Mem. no. 159.

Dowson, W. J. (1957). Plant Diseases Due to Bacteria, 2nd ed. Cambridge University Press.

Elliot, R. P. (1957). Some properties of pyoverdine, the water-soluble fluorescent pigment of the pseudomonads. Appl. Microbiol. 6, 241.

Entner, N. \& Stanier, R. Y. (1951). Studies on the oxidation of glucose by Pseudomonas fluorescens. J. Bact. 62, 181.

Entner, N. \& Doudoroff, M. (1952). Glucose and gluconic acid oxidation of Pseudomonas saccharophila. J. biol. Chem. 196, 853.

Fisher, P. J. \& ConN, J. E. (1942). A flagella staining technique for soil bacteria. Stain Tech. 17, 117.

GaBY, W. L. (1955). Taxonomic problems relating to the identification of species within the genus Pseudomonas. Int. Bull. Bact. Nomencl. 5, 153.

GabY, W. L. \& Free, E. (1953). The occurrence and identification of non-pigmented strains of Pseudomonas aeruginosa in the clinical laboratory. J. Bact. 65, 746. 
Georgia, F. R. \& Poe, C. F. (1931). Study of bacterial fluorescence in various media. I. Inorganic substances necessary for bacterial fluorescence. J. Bact. $22,349$.

Gibbs, M. \& DeMoss, R. D. (1954). Anaerobic dissimilation of ${ }^{14} \mathrm{C}$ labelled glucose and fructose by Pseudomonas lindneri. J. biol. Chem. 207, 689.

Haynes, W. C. (1951). Pseudomonas aeruginosa-its characterization and identification. J. gen. Microbiol. 5, 939.

Haynes, W. C. \& Burkholder, W. H. (1957). The genus Pseudomonas in Bergey's Manual of Determinative Bacteriology, p. 89. 7th ed. Ed. by R. S. Breed, E. G. D. Murray \& N. R. Smith. Baltimore, U.S.A.: Williams and Wilkins Co.

Haynes, W. C., Stodola, F. H., Locke, J. M., Pridham, T. G., Conway, H. C., Sohns, V. E. \& Jackson, R. W. (1956). Pseudomonas aureofaciens Kluyver and phenazine alpha-carboxylic acid, its characteristic pigment. J. Bact. 72, 412.

Hugh, R. \& Leifson, E. (1953). The taxonomic significance of fermentative versus oxidative metabolism of carbohydrates by various gram negative bacteria. J. Bact. 66, 24.

Jones, A. \& Richards, T. (1952). Night Blue and Victoria Blue as indicators in lipolysis media. Proc. Soc. appl. Bact. 15, 82.

Knight, B. C. J. G. \& Proom, H. (1950). A comparative survey of the nutrition and physiology of mesophylic species in the genus Bacillus. J. gen. Microbiol. 4, 508.

Köhler, W. (1957). Zur Serologie der Pseudomonas aeruginosa. Z. ImmunForsch. 114, 282.

Kovacs, N. (1956). Identification of Pseudomonas pyocyanea by the oxidase reaction. Nature, Lond. 178, 703.

Krassilnikov, N. A. (1949). Diagnostic of Bacteria and Actinomycetes. Moskva: Academy of Sciences U.S.S.R. (In Russian.)

Landerkin, G. B. \& Katznelson, H. (1959). Organism associated with septicaemia in the honeybee, Apis mellifera. Canad. J. Microbiol. 5, 169.

Lysenko, O. \& SNEATH, P. H. A. (1958). The use of models in bacterial classification. J.gen. Microbiol. 20, 284.

Moeller, V. (1955). Simplified tests for some amino acid decarboxylases and for the argine dihydrolase system. Acta path. microbiol. scand. 36, 158.

Naylor, J. (1954). Studies on plant pathogenic bacteria with emphasis on serological identification. M.Sc. Thesis, University of Melbourne.

Norris, F. C. \& Campbell, J. J. R. (1949). The intermediate metabolism of Pseudomonas aeruginosa. III. The application of paper chromotography to the identification of gluconic and 2-ketogluconic acid intermediates in glucose oxidation. Canad. J. Res. C, $27,53$.

Novelli, A. (1953). New method of staining bacterial capsules in films and sections. Experimentia, 9, 34 .

Paliferoni, N. J. \& Doudoroff, M. (1957). Metabolism of carbohydrates by Pseudomonas saccharophila. III. Oxidation of D-arabinose. J. Bact. 74, 180.

REPort (1958). Report of the Enterobacteriaceae Subcommittee of the Nomenclature Committee of the International Association of Microbiological Societies. Int. Bull. Bact. Nomencl.. 8, 25.

Rhodes, M. E. (1958). The cytology of Pseudomonas spp. as revealed by a silver-plating staining method. J. gen. Microbiol. 18, 639.

RHodes, M. E. (1959). The characterisation of Pseudomonas fluorescens. J. gen. Microbiol. 22, 221.

Seleen, W. A. \& Stark, C. N. (1943). Some characteristics of green fluorescent pigmentproducing bacteria. J. Bact. 46, 491.

Sherris, J. C., Shoesmith, J. G., Parker, M. T. \& Breckon, D. (1959). Tests for the rapid breakdown of arginine by bacteria : their use in the identification of pseudomonads. J. gen. Microbiol. 21, 389.

Shewan, J. M., Hodkiss, W. \& Liston, J. (1954). A method for the rapid differentiation of certain non-pathogenic asporogenous bacilli. Nature, Lond. 173, 208.

Simon, R. D. (1956). The use of fermentation reactions and pigment production to differentiate between types of Pseudomonas pyocyanea and other Pseudomonas spp., especially fluorescens. Brit. J. exp. Path. 37, 494. 
Sneath, P. H. A. (1956a). Cultural and biochemical characteristics of the genus Chromobacterium. J. gen. Microbiol. 15, 70.

SNeath, P. H. A. (1956b). The change from polar to peritrichous flagellation in Chromobacterium spp. J. gen. Microbiol. 15, 99.

SNeath, P. H. A. (1957). The application of computers to taxonomy. J. gen. Microbiol. $17,201$.

Sneath, P. H. A. \& Cowan, S. T. (1958). An electro-taxonomic survey of bacteria. J. gen. Microbiol. 19, 551.

StanIER, R. Y. (1947). Acetic acid production from ethanol by fluorescent pseudomonads. J. Bact. 54, 191.

StarR, M. P. (1946). The nutrition of phytopathogenic bacteria. I. Minimal nutritive requirements of the genus Xanthomonas. J. Bact. 51, 131.

STEEL, R. \& WALKER, T. K. (1957). A comparative study of cellulose-producing cultures and celluloseless mutants of certain Acetobacter spp. J. gen. Microbiol. 17, 445.

Stevenson, J. P. (1959). A note on the genus Aeromonas. J. gen. Microbiol. 21, 366.

ToBIE, W. C. (1938). The pigment of Bacillus violaceus. III. The apparent relation of violacein to indigo. J. Bact. 35, 11.

Topley and Wilson's Principles of Bacteriology and Immunity (1946). 3rd ed. Ed. G. S. Wilson \& A. A. Miles. Baltimore, U.S.A.: Williams and Wilkins Co.

TURFITT, G. (1936). Bacteriological and biochemical relationships in the pyocyaneousfluorescens group. I. The chromogenic function in relation to classification. Biochem. J. 30, 1323.

Wetmore, P. W. \& Gochenour, W. S. (1956). Comparative studies of the genus Malleomyces and selected Pseudomonas species. I. Morphological and cultural characteristics. J. Bact. 72, 79.

\section{EXPLANATION OF PLATE}

Plate 1

Fig. 1. Taxonomic model of the Pseudomonas sp. The model is made according to the $\mathbf{S}$ values given in Table 3. The distances $(d)$ between species represented by balls are converted from the $\mathrm{S}$ values, $d=(1 / \mathrm{S})-1$. The numbers are those used for the species in Tables 1 and 3.

Fig. 2. Taxonomic model of the Pseudomonas species: another view.

Fig. 3. Taxonomic model of Aeromonas sp. and Pseudomonas synxantha and $P$. aeruginosa. Models made according to the $\mathrm{S}$ values given in Table 4. The letters are those used for the species in Tables 2 and 4.

Fig. 4. Taxonomic model of the Aeromonas sp., Pseudomonas synxantha and $P$. aeruginosa: another view. 


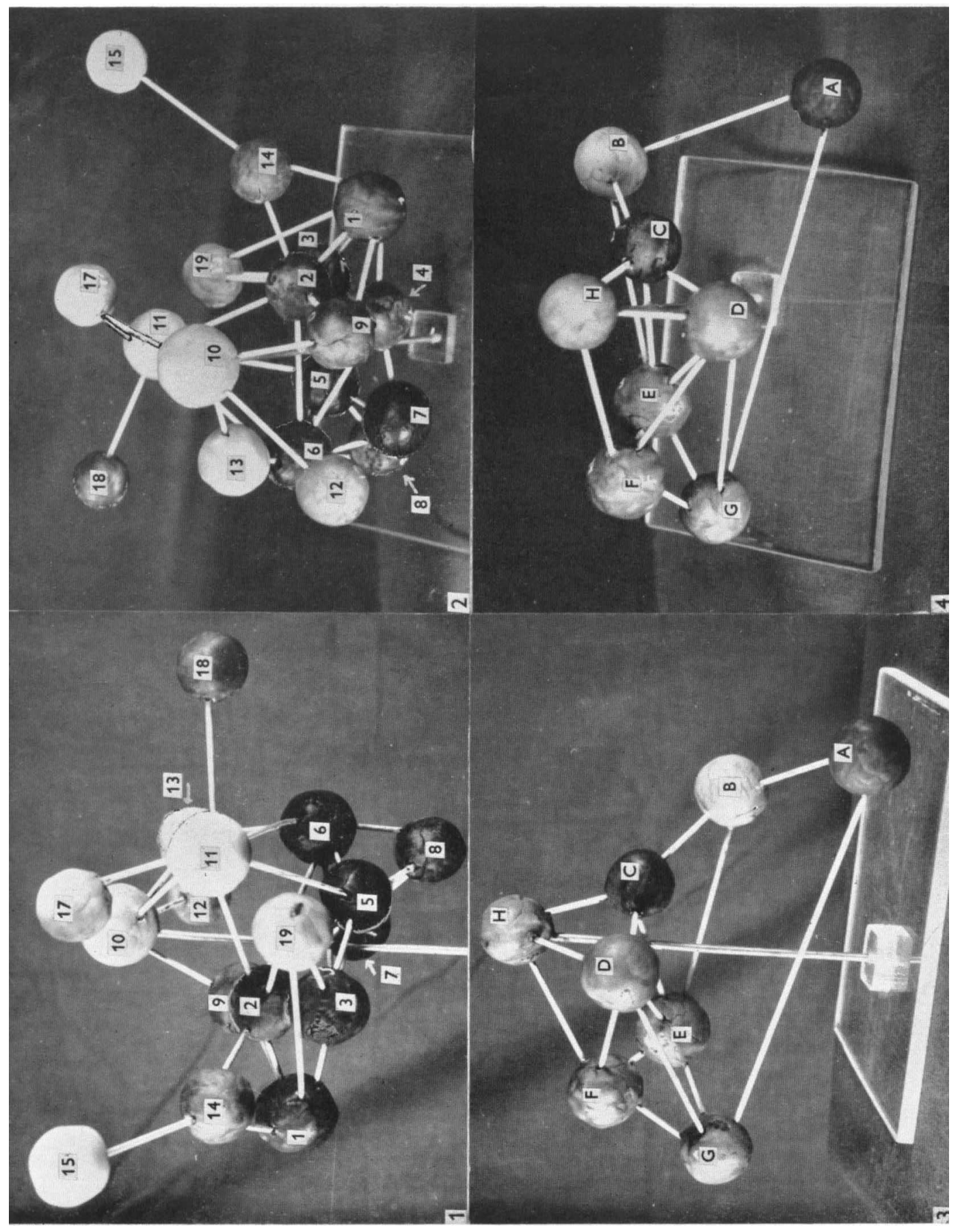

